\title{
Usando o controle de temperatura para a obtenção do efeito hydra numa população bacteriana (Bacillus E16)
}

\author{
Bruna P. Alves Berenice C. Damasceno \\ Depto de Matemática, FEIS, UNESP \\ 15385-000, Ilha Solteira, SP \\ E-mails: bruna_pardim@yahoo.com.br berenice@mat.feis.unesp.br
}

\author{
Grace H. Conceição Heloiza F. A. do Prado \\ Depto de Fitotecnia, Tecnologia de Alimentos e Sócio Economia, FEIS, UNESP \\ 15385-000, Ilha Solteira, SP \\ E-mails: hingridbergy@gmail.com heloiza@agr.feis.unesp.br
}

\begin{abstract}
RESUMO
Este trabalho refere-se ao estudo do efeito Hydra em Ecologia e sua aplicação numa cultura de Bacillus E16.

O fenômeno descrito como "efeito hydra" (cf. em [1]) (onde hydra refere-se ao ser mitológico que tendo a cabeça decepada, outras aparecem em maior quantidade) apareceu primeiro no estudo do crescimento populacional em Ecologia.

É consenso geral, que o aumento da taxa de mortalidade em uma população acarreta a diminuição do seu tamanho ao longo do tempo. Como mostrado em [6] e [4], isto é verdade em todo o modelo do tipo não estruturado contínuo de crescimento, densidade-dependente, em um meio constante, da forma:
\end{abstract}

$$
\frac{d N}{d t}=N f(N)-k N
$$

onde $N$ é o tamanho da população, $f$ é a taxa de crescimento per-capita e $k$ é uma taxa de mortalidade adicional dependente da densidade da população.

Na década de 1950 e mais intensamente na década de 1970 foram estabelecidos alguns modelos na literatura [7] em que mesmo com o crescimento da taxa de mortalidade no tempo, a população aumentava em determinados intervalos. Recentemente resultados envolvendo o efeito hydra foram também considerados em [1], [2] e [5].

Introduzimos a seguir, o modelo com gerações discretas e crescimento populacional dependente da densidade (v. (1) em [5]). Trabalharemos neste artigo com este modelo.

A equação da variação populacional que representa o modelo com gerações discretas e crescimento populacional dependente da densidade é dada recursivamente por:

$$
x_{n+1}=g\left(k_{0}\right) x_{n} f\left(g\left(k_{0}\right) x_{n}\right),
$$

onde $x_{n}$ é o tamanho da população no tempo $t_{n}, n \in \mathbb{N}$, com $f: \mathbb{R} \rightarrow \mathbb{R}, g:[0,1] \rightarrow[0,1]$ e $t_{0}>t_{1}>\cdots t_{m-1}>t_{m}>\cdots$.

Neste modelo há casos em que o efeito hydra surge como pode ser visto no seguinte resultado:

Teorema 1 [3]: Sejam $g:[0,1] \rightarrow[0,1]$ uma função decrescente, $f: \mathbb{R}^{+} \rightarrow \mathbb{R}^{+}$diferenciável com $f^{\prime}<0$. Então, se para cada $k_{0}$ fixo, vale $f(x)>\frac{1}{g\left(k_{0}\right)}$, para todo $x \in \mathbb{R}^{+}$, surge em (1) o efeito hydra. Além disso, temos que existe um intervalo fechado em que $k_{0}$ pode variar e o efeito persiste. 
Como o efeito hydra é considerado no âmbito de trabalhos em Ecologia um paradoxo [1], este teorema nos mostra que há pelo menos uma explicação ao menos "teórica" para o fenômeno em modelos com gerações discretas e com crescimento populacional dependente da densidade.

Então, a pergunta natural que surge diante deste tipo de resultado "teórico" é a seguinte: que tipo de população satisfaz a condição suficiente expressa no teorema?

Há indícios experimentais preliminares de que em populações de bactérias alcalófilas é possível obter as condições suficientes do Teorema 1.

O resultado principal neste artigo é o começo de uma resposta à pergunta acima e consiste na modelagem da variação da população do Bacillus $s p$, subgrupo alcalophilus E16 (abreviadamente Bacillus E16) quando submetida ao controle temperatura e PH.

A análise dos dados focará as situações controladas em que surge o efeito hydra.

A experiência de contagem para efeitos do estabelecimento de um modelo já está sendo realizada no Laboratório de Biotecnologia, UNESP - Campus de Ilha Solteira.

Palavras-chave: Efeito Hydra, Bacillus E16, Sobrevivência, Mortalidade.

\section{Referências}

[1] P.A. Abrams, C. Quince. The impact of mortality on predator population size and stability in systems with stage structured prey. Theor. Pop. Biol., 68, 253-266, (2005).

[2] P. A. Abrams, When does greater mortality increase population size? The long history and diverse mechanisms underlying the hydra effect. Ecology Letters, 12:464-474, (2009).

[3] G. H. Conceição, B. C. Damasceno, L. Barbanti, O Paradoxal Efeito Hydra em Populações: Aumento do Número de Indivíduos enquanto Aumenta a Taxa de Mortalidade. Anais CMAC-Sul, p.234-236, 2014.

[4] A. Hastyings. Population biology: Concepts and models, Springer, NY, 1997.

[5] E. Liz. Bubbles, chaos, and the hydra effect in delayed populational models. Colloquium on Diff. Eq. and Integration Theory, Krystni CZ, Masarykova Un. Press, p.46, 2010.

[6] H. Seno. A paradox in discrete single species population dynamics with harvesting/thinning. Math. Biosci., 214, 63-69, (2008).

[7] J. M. Smith. Models in Ecology, Cambridge University Press, Cambridge, UK, 1974. 